\title{
Efeitos da terapia vocal com tubo de ressonância na Doença de Parkinson: ensaio clínico
}

\section{RESUMO}

Introdução: A Doença de Parkinson (DP) é uma doença neurodegenerativa, lenta e progressiva. Sua manifestação envolve sinais motores que são base para o diagnóstico da doença e incluem bradicinesia, tremor e rigidez como as principais características. Estima-se que $90 \%$ dos indivíduos com DP apresentam modificações na comunicação oral, com alterações de fluência, diminuição da velocidade de fala, redução na intensidade vocal, falta de modulação de frequência, qualidade vocal alterada e outras alterações que caracterizam a disartria hipocinética, alterando a qualidade de vida. A literatura evidencia que a fonação em tubos de vidro é efetiva em diversos tipos de tratamentos e pode ser uma forma de tratar os aspectos vocais de indivíduos com DP, porém faltam estudos que comprovem a efetividade dessa intervenção na DP. Objetivo: verificar o efeito da terapia com tubo de ressonância nos aspectos vocais em indivíduos com Doença de Parkinson. Delineamento do estudo: ensaio clínico, controlado e comparativo intrassujeitos. Método: participaram 14 indivíduos com DP (dez homens e quatro mulheres) com média de idade de 66,1 anos (homens) e 73,75 (mulheres). Todos os participantes receberam oito sessões de terapia vocal, duas vezes por semana, com duração de 45 minutos. A terapia foi composta por exercício de trato vocal semiocluído método fonação em tubo de ressonância (vidro), imerso em água. As avaliações foram realizadas: 30 dias antes (momento Pré0), um dia antes (momento Pré1) e um dia após a intervenção fonoaudiológica. As avaliações constaram de avaliação dos sintomas vocais e laringofaríngeos, gravação da voz (vogal /a/ e contagem) para análise perceptivo-auditiva da qualidade vocal e acústica dos parâmetros cepstrais e espectrais, avaliação da intensidade vocal, avaliação da qualidade de vida em voz e autoavaliação vocal. Os dados foram analisados estatisticamente, comparando-se os momentos de avaliação $(p \leq 0,05)$. Resultados: A terapia vocal proporcionou resultados positivos verificados pela redução dos sintomas vocais e laringofaríngeos, nas subescalas limitação, emocional e escore total após a intervenção. A análise perceptivo-auditiva evidenciou melhora da qualidade vocal no parâmetro grau geral da vogal sustentada e a análise acústica evidenciou aumento da diferença L1 -L0 na vogal sustentada e na contagem de números. Na contagem de números ainda foi possível observar aumento da média de valores da Proeminência do Pico Cepstral suavizada - (PPCs) e aumento da intensidade vocal na vogal, após a intervenção. A média do protocolo de qualidade de vida em voz evidenciou aumento significante nos domínios físico, socioemocional e total no momento Pós intervenção. A avaliação da autopercepção vocal também mostrou que a intervenção foi efetiva para melhorar a autopercepção dos participantes em relação a voz, passando de "razoável" para "boa". Conclusão: Os resultados permitem concluir que a terapia vocal por meio da fonação em tubo de ressonância tem efetividade nos sintomas vocais e laringofaríngeos, na voz e na autopercepção vocal, bem como da qualidade de vida em voz de indivíduos com Doença de Parkinson. A terapia vocal também mostrou efetividade na melhora da autoavaliação vocal dos participantes.

Palavras-chave: Doença de Parkinson. Voz. Tratamento. Terapia 